\title{
Exendin-4 Promotes Survival of Mouse Pancreatic $\beta$-Cell Line in Lipotoxic Conditions, through the Extracellular Signal-Related Kinase 1/2 Pathway
}

\author{
Jianqiu Gu, ${ }^{1}$ Qian Wei, ${ }^{2}$ Hongzhi Zheng, ${ }^{2}$ Xin Meng, ${ }^{1}$ Jin Zhang, ${ }^{1}$ and Difei Wang ${ }^{2}$ \\ ${ }^{1}$ Department of Endocrinology, The First Affliated Hospital of China Medical University, 155 Nanjingbei Street, \\ Heping District, Shenyang, Liaoning 110001, China \\ ${ }^{2}$ Department of Geriatric Endocrinology, The First Affiliated Hospital of China Medical University, 155 Nanjingbei Street, \\ Heping District, Shenyang, Liaoning 110001, China
}

Correspondence should be addressed to Difei Wang; wdf8lm@163.com

Received 28 March 2016; Revised 11 June 2016; Accepted 11 July 2016

Academic Editor: Eusebio Chiefari

Copyright ( $(2016$ Jianqiu Gu et al. This is an open access article distributed under the Creative Commons Attribution License, which permits unrestricted use, distribution, and reproduction in any medium, provided the original work is properly cited.

Type 2 diabetes is a heterogeneous disorder that develops as a result of relatively inappropriate insulin secretion and insulin resistance. Increased levels of free fatty acids (FFAs) are one of the important factors for the pathogenesis of type 2 diabetes and contribute to defective $\beta$-cell proliferation and increased $\beta$-cell apoptosis. Recently, glucagon-like peptide-1 (GLP-1) receptor agonists have been shown to possess an antiapoptotic effect, by increasing $\beta$-cell mass and improving $\beta$-cell function. However, their effects on $\beta$-cells in vitro against lipotoxicity have not been elucidated completely. In this study, we investigated whether the GLP-1 receptor agonist exendin- 4 displays prosurvival effects in pancreatic $\beta$-cells exposed to chronic elevated FFAs. Results showed that exendin-4 inhibited apoptosis induced by palmitate in MIN6 cells. After $24 \mathrm{~h}$ of incubation, exendin-4 caused rapid activation of extracellular signal-related kinase 1/2 (ERK1/2) under lipotoxic conditions. The ERK1/2 inhibitor PD98059 blocked the antilipotoxic effect of exendin-4 on MIN6 cells. Exendin-4 also inhibited the mitochondrial pathway of apoptosis. This inhibition is associated with upregulation of BCL-2. Our findings suggested that exendin-4 may exert cytoprotective effects through activation of ERK1/2 and inhibition of the mitochondrial apoptosis pathway.

\section{Introduction}

Type 2 diabetes is a heterogeneous disorder characterized by peripheral insulin resistance, defects in insulin secretion, and $\beta$-cell apoptosis. Pancreatic $\beta$-cell dysfunction is central to the pathogenesis of type 2 diabetes, and the loss of functional $\beta$-cell mass in type 2 diabetes is at least in part secondary to increased $\beta$-cell apoptosis. Obesity is a wellknown risk factor for diabetes and is characterized by elevated levels of circulating free fatty acids (FFAs) [1]. Prolonged exposure to elevated levels of FFAs has been shown to cause defective $\beta$-cell proliferation and increased $\beta$-cell apoptosis. Therefore, lipotoxicity plays an important role in underlying the mechanism of type 2 diabetes.

Glucagon-like peptide-1 (GLP-1), an incretin hormone secreted by intestinal L-cells, is a recent modality for the treatment of type 2 diabetes. GLP- 1 and its receptor agonists exhibit a variety of benefits to diabetic patients. GLP-1 can be used against hyperglycemia and obesity in most T2DM diabetic patients by stimulating insulin secretion, inhibiting glucagon secretion, slowing gastric emptying, and promoting satiety [2]. Among all these effects, the major target of GLP-1 actions is the pancreatic $\beta$-cell [3-5]. GLP-1 has been found to promote $\beta$-cell proliferation $[6,7]$. Furthermore, recent data have shown that GLP-1 and its receptor agonists promote the survival of $\beta$-cell lines when challenged with various apoptotic stimulators, including hyperglycemia, inflammatory cytokines, oxidative stress, and endoplasmic reticulum stress [8-10]. However, until now whether exendin-4, a GLP1 receptor agonist, exerts cytoprotective effects in pancreatic $\beta$-cells under lipotoxic condition had not been determined completely. 
Therefore, the aim of the present study was to investigate the potential antiapoptotic and prosurvival actions of exendin- 4 in pancreatic $\beta$-cells under a chronic lipotoxic condition and the underlying signaling pathways involved.

\section{Materials and Methods}

2.1. Materials. Exendin-4 was purchased from Prospec (Rehovot, Israel). Fatty-acid-free bovine serum albumin (BSA, fraction V), palmitate, Hoechst33258, 3-(4,5-dimethylthiazol-2-yl)-2,5-diphenyltetrazolium bromides (MTT), and PD98059 were purchased from Sigma-Aldrich (St. Louis, MO, USA). The anti-phospho-ERK1/2 and anti-total ERK1/2 antibodies were obtained from Cell Signaling Technology (Danvers, MA, USA). The anti-BAX and anti-BCL-2 antibodies were obtained from Santa Cruz Biotechnology (Heidelberg, Germany). An enzyme-linked immunosorbent assay(ELISA-) based bromodeoxyuridine (BrdU) incorporation kit was from Roche (Basel, Switzerland). The caspase-3 activity assay kit was from R\&D Systems (Minneapolis, MN, USA).

2.2. Cell Culture. Mouse pancreatic $\beta$-cell line MIN6 was a kind gift from Biochemistry Lab of China Medical University with passage number of 10 to 20 . They were maintained in Dulbecco modified Eagle medium (DMEM) containing $25 \mathrm{mM}$ glucose, $15 \%$ fetal bovine serum (FBS), $100 \mathrm{U} / \mathrm{mL}$ penicillin, $100 \mathrm{mg} / \mathrm{mL}$ streptomycin, $100 \mathrm{mg} / \mathrm{mL} \mathrm{L}$ glutamine, and $5 \mu \mathrm{g} / \mathrm{L} \beta$-mercaptoethanol in a $37^{\circ} \mathrm{C}$ humidified atmosphere with $5 \% \mathrm{CO}_{2}$ and $95 \%$ air. Cells at $80 \%$ confluence were washed with phosphate-buffered saline (PBS) and preincubated overnight in serum-free DMEM before treatment. Followed assays were conducted as designed.

2.3. Fatty Acid, Exendin-4, and ERK1/2 Inhibitor Treatment of MIN6 Cells. MIN6 cells were cultured in a high glucose $(25 \mathrm{mM})$ serum-free DMEM with $0.5 \%$ BSA or $0.4 \mathrm{mM}$ palmitate added $0.5 \%$ BSA, with or without ERK1/2 inhibitor, in the presence or absence of exendin- 4 . The $0.4 \mathrm{mM}$ palmitate fatty acid solution was prepared as described previously [11]. Briefly, a $20 \mathrm{mM}$ solution of palmitate in $0.01 \mathrm{M} \mathrm{NaOH}$ was incubated at $70^{\circ} \mathrm{C}$ for $30 \mathrm{~min}$. Then $330 \mu \mathrm{L} \mathrm{30 \%} \mathrm{BSA} \mathrm{and}$ $400 \mu \mathrm{L}$ palmitate $/ \mathrm{NaOH}$ mixture were mixed together, filtersterilized, and added into $20 \mathrm{~mL}$ DMEM. The concentration of BSA was $0.5 \%$ in all medium. We selected a $25 \mathrm{mM}$ glucose concentration for all tests because an increased glucose concentration was essential for MIN6 proliferation, and $25 \mathrm{mM}$ glucose protected MIN6 cells from apoptosis [12]. Graded doses of exendin-4 (1, 10, 100, and $500 \mathrm{nM})$ were prepared freshly before tests. The ERK1/2 inhibitor used in the study was PD98059 $(50 \mu \mathrm{M})$.

2.4. Cell Viability Assay. Cell viability was assessed by MTT as described previously [13]. 5000 cells per well were set up onto 96-well plates. Before detection, cells were incubated with $1 \mathrm{mg} / \mathrm{mL}$ MTT for $1 \mathrm{~h}$. The medium was removed and the formazan product was solubilized with $150 \mu \mathrm{L}$ dimethyl sulfoxide. Viability was assessed by spectrophotometry at $570 \mathrm{~nm}$ absorbance using a 96-well plate reader.
2.5. Cell Proliferation Assay. Proliferation of MIN6 cells was evaluated with an ELISA-based BrdU incorporation kit. Briefly, MIN6 cells were set up onto 96-well plates at $80 \%$ confluence and incubated overnight in serum-free DMEM before experiments, and BrdU was added to the culture medium for $1 \mathrm{~h}$ before cells harvest. Cells were then fixed and incubated with a peroxidase-conjugated anti-BrdU antibody, and immune complexes were quantified by spectrophotometry.

2.6. Hoechst33258 Assay. Apoptosis was evaluated by Hoechst33258 staining. The Hoechst positive cells represent the apoptotic cells, which were characterized with chromatin condensation or fragmented nuclear membrane. Briefly, Hoechst staining was performed by exposing the cell slides to $10 \mu \mathrm{g} / \mathrm{mL}$ Hoechst 33258 for $10 \mathrm{~min}$ at room temperature. The cells were counted by fluorescence microscopy after staining.

2.7. Caspase-3 Activity Assay. Caspase-3 activity was measured in triplicate with a Caspase-3 Colorimetric Assay kit, according to the manufacturer's manual. In brief, after two time washes with ice-cold PBS, cells were harvested and centrifuged at 10,000 rpm for $10 \mathrm{~min}$, followed by the addition of $1 \mu \mathrm{L}$ dithiothreitol (DTT) and $100 \mu \mathrm{L}$ lysis buffer. Cell lysates were placed in a 96-well plate and incubated for $2 \mathrm{~h}$ at $37^{\circ} \mathrm{C}$ with $10 \mu \mathrm{L}$ Caspase-3 Colorimetric Substrate (DEVDpNA). Absorbance at $405 \mathrm{~nm}$ was measured with a 96-well plate reader.

2.8. Western Blot. Western blotting was carried out as described previously [12]. Briefly, protein was extracted with a cell lysis buffer. $50 \mu \mathrm{g}$ protein samples (in $20 \mu \mathrm{L}$ buffer) were separated by SDS-electrophoresis on $12 \%$ gradient polyacrylamide gels and transferred onto PVDF membranes. The membranes were incubated with the primary antibodies with appropriate concentration, including antiphospho-ERK1/2 antibody $(1: 1,000)$, anti-total ERK1/2 antibody $(1: 1,000)$, anti-BAX antibody $(1: 200)$, and anti-BCL2 antibody $(1: 200)$. Immunodetection was performed with ECL advance, and resulting images were analyzed by Scion Image software version 4.0.3.2 (Scion Corporation, Frederick, $\mathrm{MD})$.

2.9. Statistical Analysis. All data are presented as mean \pm standard error (SE). Statistical analyses were performed with SPSS software version 13.0 (SPSS Inc., Chicago, IL) with statistical significant set at $p<0.05$. Differences between groups were determined by one-way analysis of variance (ANOVA) followed by post hoc testing and correction by least significant difference/Dunnett's $t$-test. If the $F$ ratio was statistically significant, a Turkey's post hoc test was considered.

\section{Results}

3.1. Exendin-4 Promotes MIN6 Cells Survival under Lipotoxic Condition. To determine the effects of exendin- 4 on $\beta$-cell 


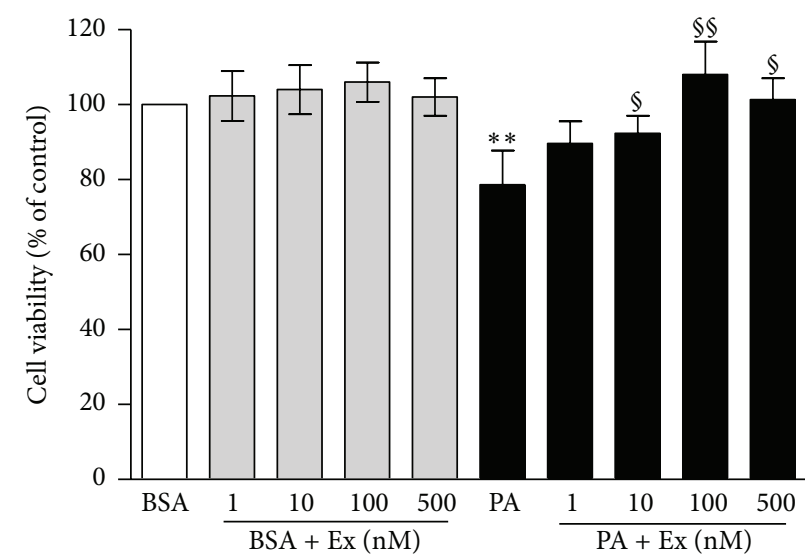

(a)

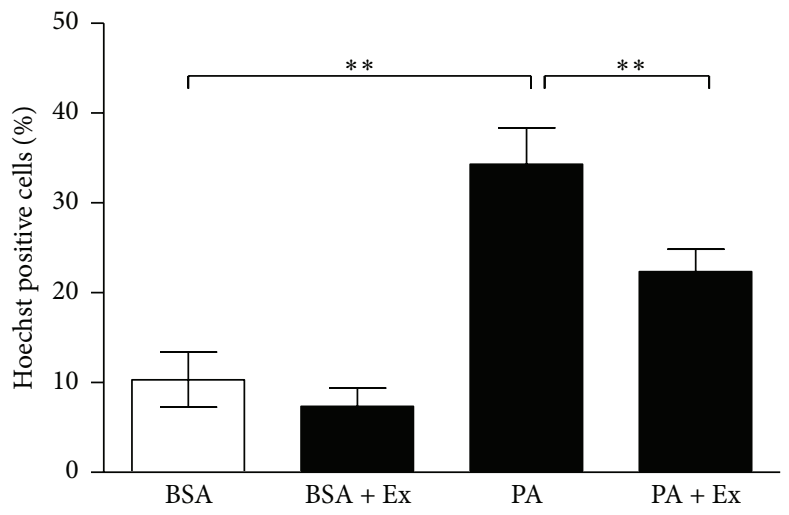

(c)

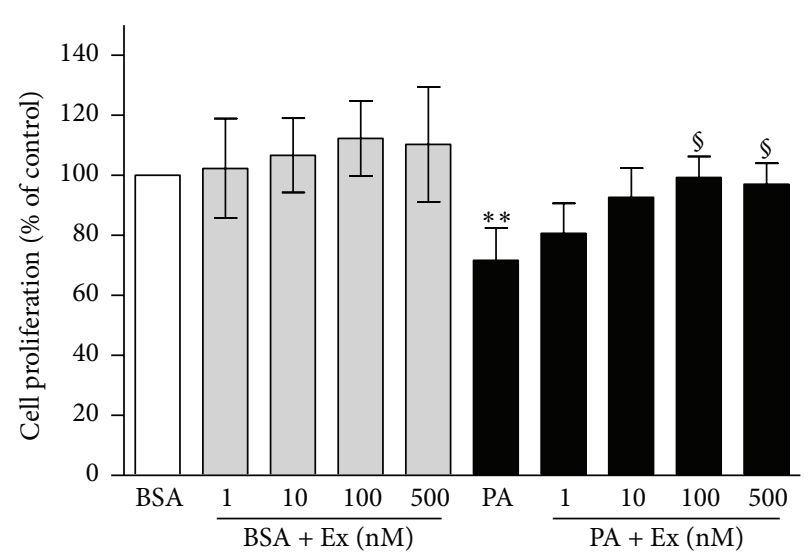

(b)

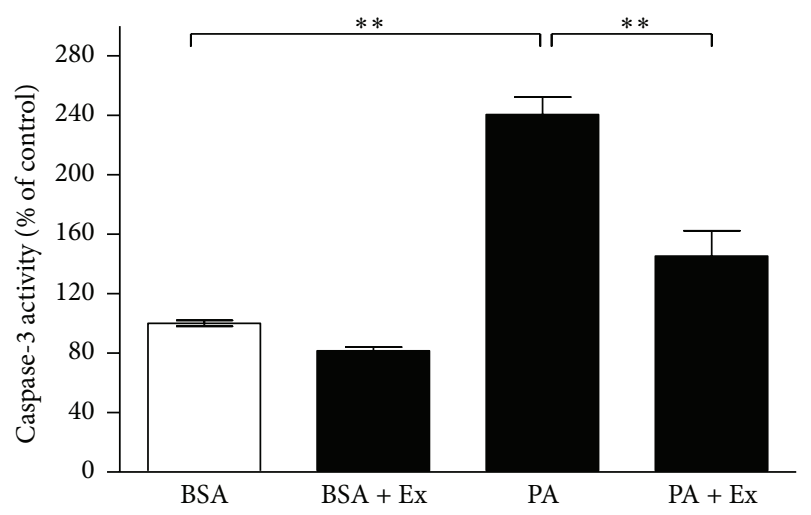

(d)

FIGURE 1: Exendin-4 inhibits apoptosis in palmitate-treated MIN6 cells. MIN6 cells were incubated in 0.5\% BSA (BSA) or 0.4 mM palmitate added $0.5 \%$ BSA (PA), in the presence or absence of increasing concentrations of exendin-4 (1-500 nM) (Ex), in serum-free DMEM for $24 \mathrm{~h}$. Exendin-4 was added at a concentration of $100 \mathrm{nM}$ for Hoechst 33258 staining and caspase- 3 activity assays. (a) Cell survival was assessed by MTT assay. Cell survival results are expressed as percentage of control (cells treated with BSA alone) and represent the mean \pm SE of five independent experiments. ${ }^{* *} p<0.01$, versus BSA; ${ }^{\circledR} p<0.05,{ }^{\$ S} p<0.01$, versus PA. (b) Cell proliferation was evaluated by BrdU incorporation kit. Cell proliferation results are expressed as percentage of control (cells treated with BSA alone) and represent the mean \pm SE of five independent experiments. ${ }^{* *} p<0.01$ versus BSA; ${ }^{\circledR} p<0.05,{ }^{\$ \varsigma} p<0.01$, versus PA. (c) Apoptosis was evaluated by Hoechst33258 staining. Values are expressed as percentage of apoptotic cells and represent the mean \pm SE of three independent experiments. ${ }^{* *} p<0.01$. (d) Apoptosis was assessed by caspase- 3 activity assay. Values are expressed as percentage of control (cells treated with BSA alone) and represent the mean \pm SE of three independent experiments. ${ }^{* *} p<0.01$.

survival and proliferation, MIN6 cells were incubated in the $0.5 \% \mathrm{BSA}$ (BSA) and $0.4 \mathrm{mM}$ palmitate added $0.5 \% \mathrm{BSA}$ (PA), with or without increasing concentrations of exendin$4(1-500 \mathrm{nM})(\mathrm{Ex})$ for $24 \mathrm{~h}$. Cell viability and proliferation were assessed by the MTT assay and an ELISA-based BrdU incorporation kit, respectively.

Cell survival (Figure 1(a)) was significantly reduced by palmitate treatment $(28 \%, p<0.01$ versus BSA). Exendin4 treatment reversed palmitate-induced reduction of cell viability, and $100 \mathrm{nM}$ exendin-4 displayed a major effect of restoring the cell viability by $27 \%$ ( $p<0.01$ versus PA). Exendin-4 treatment alone showed a nonsignificant promotion to cell survival, and $100 \mathrm{nM}$ exendin- 4 provided the best potentiation ( $112 \%, p=0.21$ versus BSA).

Cell proliferation (Figure 1(b)) was decreased under palmitate exposure ( $38 \%, p<0.01$ versus BSA). This decrease was inhibited by exendin- 4 treatment, most obviously at $100 \mathrm{nM}(29 \%, p<0.01$ versus PA). Exendin-4 treatment alone displayed a nonsignificant increase in cell proliferation, and $100 \mathrm{nM}$ exendin- 4 provided the greatest tendency $(120 \%$, $p=0.11$ versus $\mathrm{BSA}$ ). In the presence of $\mathrm{PA}, 100 \mathrm{nM}$ exendin4 achieved a significant proliferative effect $(91 \%, p=0.03$ versus $\mathrm{PA}$ ).

We next assessed cell apoptosis by Hoechst33258 assay and caspase- 3 activity assay. For Hoechst33258 assay, MIN6 cells were incubated with or without $0.4 \mathrm{mM}$ palmitate, in the presence or absence of $100 \mathrm{nM}$ exendin- 4 (Figure 1(c)). PA exposure for $24 \mathrm{~h}$ induced apoptosis $(34.3 \%, p<0.01$ versus BSA), which was reversed by $100 \mathrm{nM}$ exendin- 4 treatment by decreasing the apoptosis to $11.9 \%(p<0.01, \mathrm{PA}+$ Ex versus PA). Similar results were found using caspase- 3 activity assay (Figure 1(d)). Apoptosis was significantly increased in cells treated with $\mathrm{PA}$ alone $(133 \%, p<0.01$, PA versus $\mathrm{BSA})$. $100 \mathrm{nM}$ exendin- 4 treatment with PA presence resulted in a significant decrease of apoptosis $(87 \%, p<0.01, \mathrm{PA}+\mathrm{Ex}$ versus $\mathrm{PA})$. 
3.2. Exendin-4 Exerts Antilipotoxic Effects through Phosphorylation of ERK1/2. We investigated the effect of exendin4 on ERK1/2 phosphorylation under palmitate treatment, by detecting the ratio of phosphorylated ERK1/2 expression to total ERK1/2 expression (Figure 2(a)). The ERK1/2 phosphorylation was blocked by palmitate exposure $(0.624 \pm$ 0.048 versus $0.496 \pm 0.062, p<0.05 \mathrm{BSA}$ versus $\mathrm{PA}+\mathrm{Ex}$ at $0 \mathrm{~min}$ ). At the end of the preincubation period, $100 \mathrm{nM}$ exendin- 4 was added. Cells were collected at indicated time points after that. Phosphorylation of ERK1/2 was increased by exendin- 4 treatment in a time-dependent manner. The maximal effect was observed at $5 \mathrm{~min}(0.721 \pm 0.135$ versus $0.496 \pm 0.062, p<0.01 \mathrm{PA}+\mathrm{Ex}$ at 5 min versus $\mathrm{PA}+\mathrm{Ex}$ at $0 \mathrm{~min}$ ).

Exendin- 4 also induced the phosphorylation of ERK1/2 in a concentration-dependent manner (Figure 2(b)) and $100 \mathrm{nM}$ exendin- 4 treatment produced the most effective potentiation $(0.744 \pm 0.083$ versus $0.494 \pm 0.117, p<0.01 \mathrm{PA}+\mathrm{Ex}$ at $100 \mathrm{nM}$ versus $\mathrm{PA})$.

To establish the induction of phosphorylation of ERK1/2 by exendin-4, we did further treatment using PD98059, a specific ERK1/2 inhibitor (Figure 2(c)). The exendin-4-induced phosphorylation of ERK1/2 was obviously suppressed by PD98059 $(0.707 \pm 0.096$ versus $0.556 \pm 0.050, p<0.05 \mathrm{Ex}+$ $\mathrm{PA}$ versus $\mathrm{Ex}+\mathrm{PD}+\mathrm{PA})$, whereas the effect of PD98059 on ERK1/2 phosphorylation without exendin- 4 was similar to that of PA alone $(0.459 \pm 0.057$ versus $0.519 \pm 0.071$, $p=0.217 \mathrm{PA}+\mathrm{PD}$ versus PA).

We also determined the role of the ERK1/2 inhibitor on the cytoprotective effect of exendin- 4 by MTT assay and Hoechst33258 assay (Figures 2(d) and 2(e)). Consistent with the aforementioned results, exendin- 4 treatment promoted cell survival $(95.3 \pm 3.7 \%$ versus $68.4 \pm 6.9 \%, p<0.01$ $\mathrm{Ex}+\mathrm{PA}$ versus PA) and prevented apoptosis of MIN6 cells $(21.2 \pm 2.1 \%$ versus $33.5 \pm 3.7 \%, p<0.01 \mathrm{Ex}+\mathrm{PA}$ versus $\mathrm{PA})$ under lipotoxic condition, whereas PD98059 suppressed this promotion of cell survival $(71.0 \pm 4.6 \%$ versus $95.3 \pm 3.7 \%$, $p<0.05 \mathrm{Ex}+\mathrm{PD}+\mathrm{PA}$ versus $\mathrm{Ex}+\mathrm{PA})$ and attenuated the restore of apoptosis $(29.2 \pm 3.2 \%$ versus $21.2 \pm 2.1 \%$, $p<0.05 \mathrm{Ex}+\mathrm{PD}+\mathrm{PA}$ versus $\mathrm{Ex}+\mathrm{PA})$ under lipotoxic condition.

All these results strongly suggested that exendin- 4 protected MIN6 cells against lipotoxicity, at least in part, via activation of ERK1/2 signaling pathway.

3.3. Antiapoptotic Effect of Exendin-4 Involves the Mitochondrial Apoptosis Pathway. Western blot analysis of BCL-2 and BAX were conducted after $24 \mathrm{~h}$ culture under lipotoxic condition (Figure 3). We found a significant decreased expression of the antiapoptotic protein BCL-2 (Figure 3(a), $p<0.01$ versus BSA) and enhanced expression of the proapoptotic protein BAX (Figure $3(\mathrm{~b}), p<0.01$ versus BSA) in MIN6 cells under palmitate treatment. While the exendin4 treatment showed a significant increased expression of BCL-2 (Figure 3(a), $p<0.05$ versus PA) and a nonsignificant decreased expression of BAX levels (Figure 3(b), $p=0.22$ versus PA), compared with the parallel lipotoxic condition cultured without exendin- 4 .

\section{Discussion}

The incretin glucagon-like peptide-1 (GLP-1), the major gastrointestinal product of proglucagon processing, has been shown to exert trophic effects on $\beta$-cells [14]. Exendin-4 is a GLP-1 receptor agonist with various capabilities including cellular protection [15]. Although roles of exendin-4 on cell proliferation and antiapoptosis have been demonstrated in $\beta$-cells, its mechanisms are not fully understood. Moreover, whether exendin- 4 protects $\beta$-cells against lipotoxicity remains to be determined. In the present study, we found that exendin- 4 inhibited palmitate-induced apoptosis via activating ERK1/2 pathway and also through inhibiting mitochondrial apoptosis pathway in the MIN6 cells.

Lipotoxicity and glucotoxicity play vital parts in type 2 diabetes [16-18]. Physiologic levels of lipids and glucose are not toxic but essential to $\beta$-cell function, while prolonged exposure of pancreatic $\beta$-cells to high levels of fatty acid impairs insulin gene expression [19], inhibits insulin synthesis and secretion [20], and induces $\beta$-cell apoptosis $[11,21,22]$. In vivo, the normal plasma concentration of FFA is less than $0.6 \mathrm{mmol} / \mathrm{L}$ but could exceed $1 \mathrm{mmol} / \mathrm{L}$ in type 2 diabetic patients $[23,24]$. Palmitate and oleate are the two most represented FFAs in plasma ( 20 to $25 \%$ each), linked to albumin in the circulation $[25,26]$. To mimic what is observed in vivo, we used a mixture of palmitate with $5 \%$ fatty-acid-free BSA. This high albumin concentration was used to obtain an appropriate albumin to nonesterified fatty acid ratio. In our study, the direct effects of long-term elevated palmitate on the survival of pancreatic $\beta$-cells were studied. We showed that palmitate markedly enhanced apoptosis and attenuated cell survival of MIN6 cells. Consistent with previous observations $[27,28]$, theoretically, antilipotoxicity through blockade of apoptosis and enhancement of proliferation may be a novel approach to protect pancreatic $\beta$-cells.

Accumulating evidence supports the role of GLP-1 mimetics and enhancers in regulating proliferation and protecting from cellular apoptosis. These agents constitute a novel class of antidiabetes medications, which might have a major impact on the treatment of type 2 diabetes [29-31]. In this study, we demonstrated that treatment with exendin- 4 , a GLP-1 agonist, protected pancreatic $\beta$-cell from palmitateinduced toxicity by enhancing proliferation and inhibiting apoptosis, in a dose-dependent manner (Figure 1). In addition, exendin- 4 treatment activated the ERK1/2 signaling pathway.

ERK1/2, a well-known downstream target of Raf-1, has been shown to participate in pathways controlling $\beta$-cell survival. It has been reported in several studies that acute glucose and protein kinase A signaling may regulate $\beta$-cell growth and survival through ERK1/2 [32-34]. On the other hand, others have shown that activation of ERK1/2 is required for human islet apoptosis in response to chronic exposure to high glucose concentrations or interleukin-1 $\beta$ [35]. Thus, ERK1/2 signaling is activated in both prosurvival and proapoptotic conditions. The outcome may depend on the timing and duration of ERK1/2 activation [36]. In the present study, our findings showed that exposure of MIN6 cells to chronic lipotoxic conditions reduced the phosphorylation of 


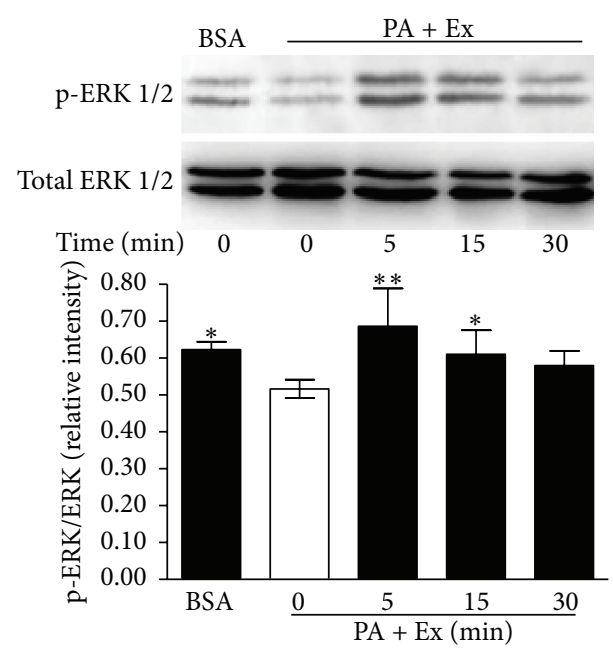

(a)

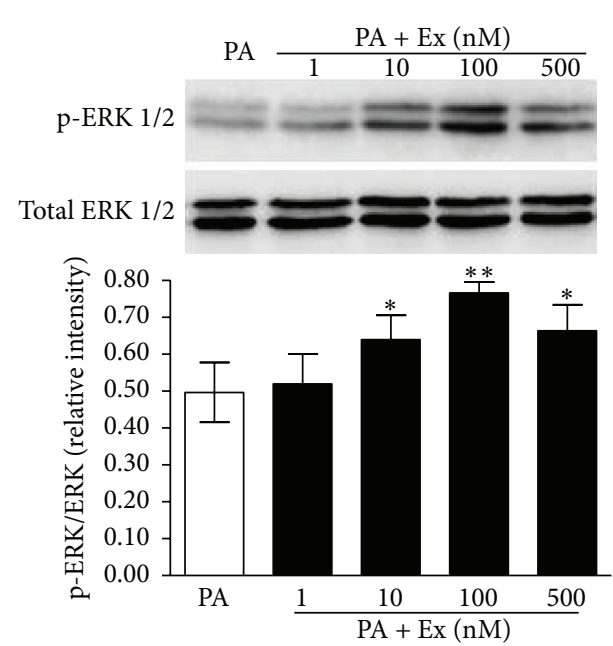

(b)

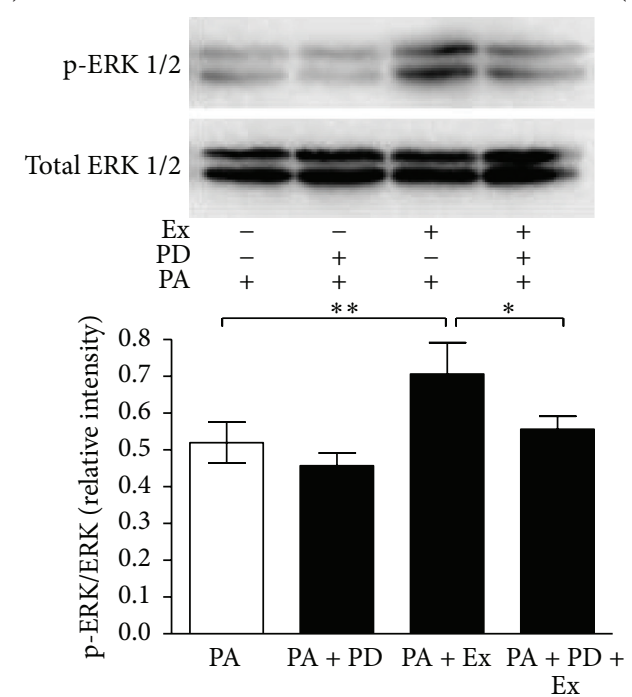

(c)

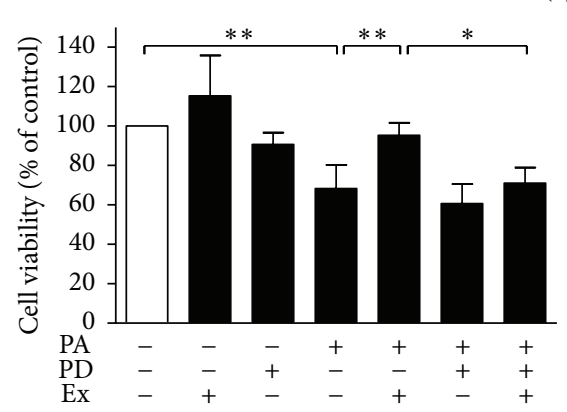

(d)

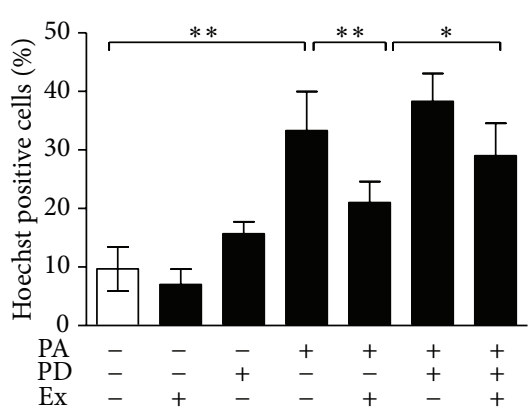

(e)

FIGURE 2: The antilipotoxic effects of exendin-4 on cell survival and apoptosis involve ERK1/2 pathway. MIN6 cells were preincubated overnight in serum-free DMEM and then incubated in serum-free DMEM containing 0.5\% BSA (BSA) or $0.4 \mathrm{mM}$ palmitate added $0.5 \%$ BSA (PA) for $24 \mathrm{~h}$. Increasing concentrations (1-500 nM) of exendin-4 (Ex) were used to treat the cells for the indicated times. (a) Total ERK1/2 and p-ERK1/2 protein expression after 0-30 min of treatment with $100 \mathrm{nM}$ Ex. Values are expressed as relative intensity ratio and represent the mean $\pm \mathrm{SE}$ of three independent experiments. ${ }^{*} p<0.05,{ }^{* *} p<0.01$, versus PA $+\mathrm{Ex}$ at 0 min. (b) Total ERK1/2 and $\mathrm{p}$-ERK1/2 protein expression after $5 \mathrm{~min}$ of treatment with increasing concentrations (1-500 $\mathrm{nM}$ ) of Ex. Values are expressed as relative intensity ratio and represent the mean $\pm \mathrm{SE}$ of three independent experiments. ${ }^{*} p<0.05,{ }^{* *} p<0.01$, versus PA group without Ex. (c) Total ERK1/2 and p-ERK1/2 protein expression after 5 min of treatment with $100 \mathrm{nM} \mathrm{Ex}$, with or without inhibitor. Before Ex stimulation, cells with PA were pretreated for $30 \mathrm{~min}$ with ERK1/2 inhibitor, $50 \mu \mathrm{M}$ PD98059 (PD). Values are expressed as relative intensity ratio and represent the mean \pm SE of three independent experiments. ${ }^{*} p<0.05,{ }^{* *} p<0.01$. (d) Cell survival was assessed by MTT assay. ${ }^{*} p<0.05,{ }^{* *} p<0.01$. (e) apoptosis assessed by Hoechst33258 staining. MIN6 cells were incubated with BSA or PA, with or without PD, in the presence or absence of $100 \mathrm{nM}$ Ex, in serum-free medium for $24 \mathrm{~h}$. Values of survival are expressed as percentage of control (cells treated with BSA alone) and represent the mean \pm SE of five independent experiments. Values of apoptosis are expressed as percentage of apoptotic cells and represent the mean \pm SE of 10 random fields of vision of three independent experiments. ${ }^{*} p<0.05,{ }^{* *} p<0.01$. 


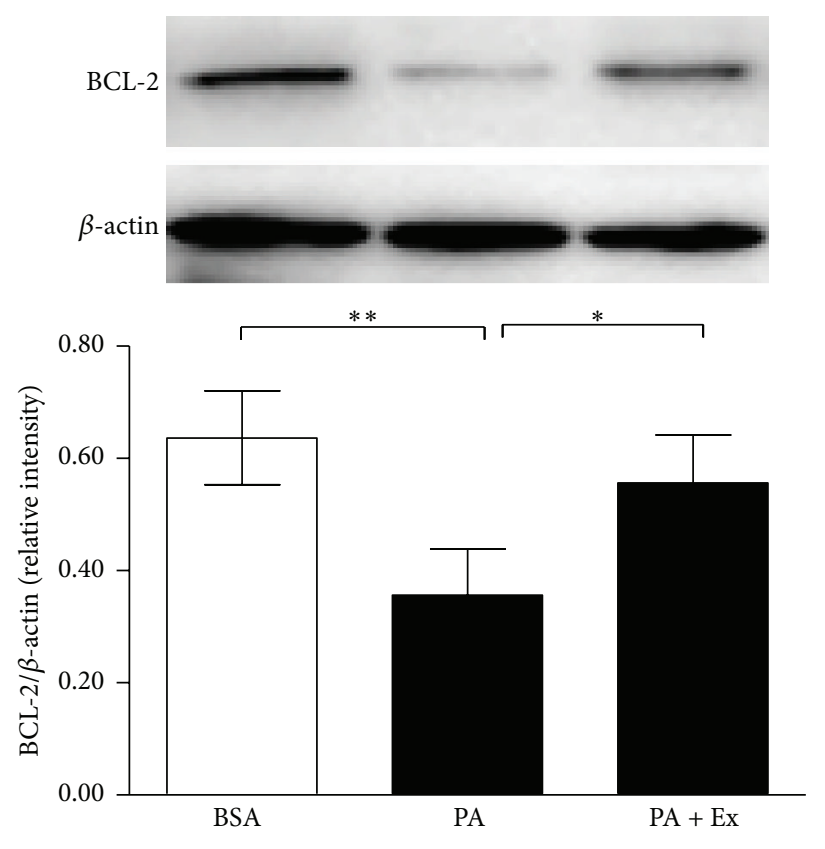

(a)

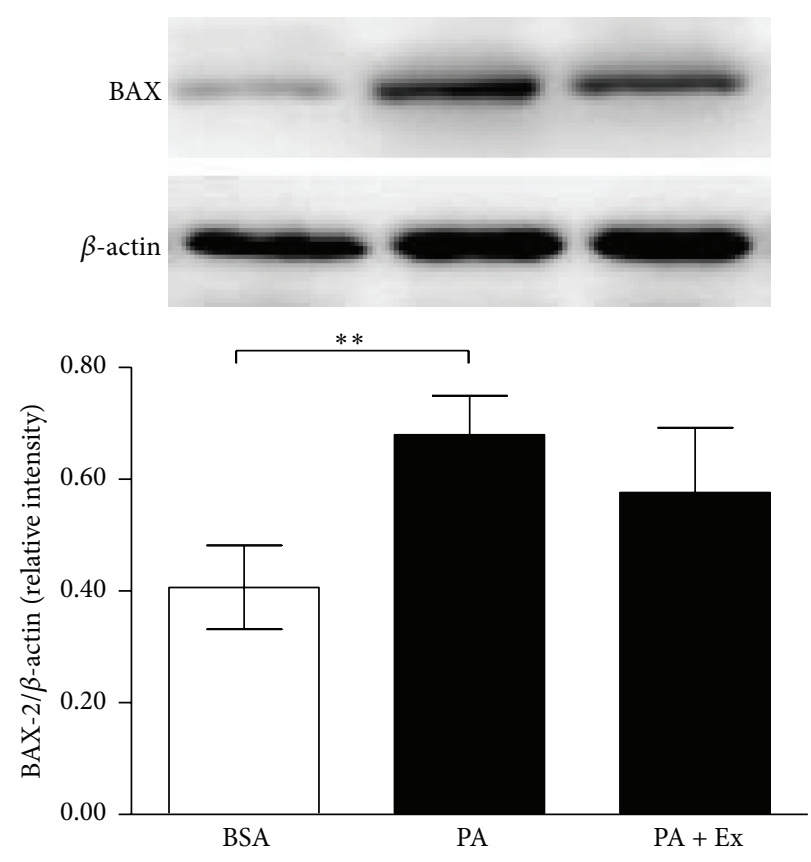

(b)

FIGURE 3: The antiapoptotic effect of exendin-4 involves the mitochondrial apoptosis pathway. MIN6 cells were incubated in serum-free DMEM with $0.5 \%$ BSA (BSA) or $0.4 \mathrm{mM}$ palmitate added $0.5 \%$ BSA (PA), with or without $100 \mathrm{nM}$ exendin-4 (Ex) for $24 \mathrm{~h}$. Protein expression of BCL-2 (a) and BAX (b) was assessed by western blot in MIN6 cells. Values are expressed as relative intensity ratio of BCL-2 or BAX to $\beta$-actin and represent the mean \pm SE of three independent experiments. ${ }^{*} p<0.05,{ }^{* *} p<0.01$.

ERK1/2. In addition, this reduction was reversed by exendin4 treatment through a rapid activation of ERK1/2. Further treatment with the ERK1/2 inhibitor PD98059 blocked this protective effect of exendin-4 (Figure 2). These data indicate that exendin-4 exerted cytoprotective effect on pancreatic $\beta$-cells against lipotoxicity, at least in part via the ERK1/2 pathway.

The mechanisms underlying apoptosis are regulated by defined biochemical pathways, involving members of the BCL-2 family [37]. In mammalian cells, the BCL-2 family of proteins plays a central role in modulating mitochondrialdependent apoptosis. Both prosurvival and proapoptotic BCL-2 family members are critical death regulators via mitochondrial apoptosis pathway [38]. Among BCL-2 family proteins, prosurvival BCL-2 stabilizes the mitochondrial membrane and prevents the cytochrome $\mathrm{C}$ release from the mitochondria and the followed activation of caspases. In the present study, BCL-2 was found to be downregulated and the proapoptotic BAX was upregulated, which was in accordance with the increased activity of caspase-3 under lipotoxic condition. After exendin-4 treatment, we observed that these alterations were partially counteracted (Figure 3 ). So, our results indicate that exendin- 4 conducts its protective effect through inhibiting mitochondrial apoptosis pathway, by promoting BCL-2 protein expression. This finding may provide further insight into the mechanisms of cytoprotective effect of exendin- 4 .

Interestingly, some BCL-2 family proteins were found to be involved in Erk1/2 signaling pathway. As reviewed by Cagnol and Chambard [39], proapoptotic proteins BAD and BAX were found to be activated by Erk1/2 activation. In contrast, antiapoptotic proteins BCL-2 and BCL-Xl were downregulated by ERK1/2 activation. On the other hand, phosphorylation of proapoptotic protein $\mathrm{BAD}$ was assumed to be involved in ERK1/2 promoted cell survival [40]. In human pancreatic cancer cells, inhibition of ERK1/2 activities caused downregulation of antiapoptotic proteins BCL2, MCL-1, and BCL-Xl without affecting the proapoptotic proteins BAX and BAK [41]. These various reports might be interpreted depending on different cell types or conditions. In our study, we found both ERK1/2 activation and enhanced BCL- 2 expression induced by exendin- 4 treatment under lipotoxic condition. Further study on the relation between ERK1/2 activation and inhibition of mitochondrial apoptosis pathway may reveal more detailed molecular mechanism of GLP-1 mediated cytoprotective role on pancreatic $\beta$-cells. Another defect of our study is the MIN6 cell line we used. MIN6 is an insulinoma cell line derived from a C57BL/6 transgenic mouse [42]. Compared to other insulin-secreting cell lines, MIN6 cells express GLUT-2 and glucokinase and display a similar glucose stimulating insulin secretion to normal primary $\beta$-cells [43]. The insulin secretion of MIN6 cells reaches the maximal level approximately sevenfold above the basal level at $25 \mathrm{mmol} / \mathrm{L}$ [42], which is consistent with the performance of our MIN6 cells (data not shown). But as an immortalized cell line, some of its characters, especially the proliferative specific, are not exact same with primary $\beta$ cells. This could be a confounding factor within any study on this aspect. So further confirmatory study using primary $\beta$ cells is needed. 


\section{Conclusion}

In conclusion, it is likely that exendin- 4 induced ERK1/2 activation is an important pathway, by which exendin-4 exerts antiapoptotic actions against palmitate-induced lipotoxicity. Besides, the potential cytoprotective effect of exendin-4 on $\beta$-cells involves the mitochondrial apoptosis pathway, by upregulating BCL-2. Because lipotoxicity is supposed to be responsible for $\beta$-cell loss in the pathological process of obesity-associated type 2 diabetes, the antilipotoxic effects on residual $\beta$-cells of exendin- 4 may arouse interest, considering its therapeutic utilization in type 2 diabetes treatment.

\section{Competing Interests}

The authors do not have any potential conflict of interests associated with this research.

\section{Acknowledgments}

This work is supported by the National Natural Science Foundation of China (81370905, 81400839), the science and technology projects of Liaoning Province (2012225079, 2012225020, 2015225024), and the science and technology projects of Shenyang City (F13-220-9-02). The authors thank the Biochemical Department of China Medical University for valuable suggestions and help in the study.

\section{References}

[1] A. E. Butler, J. Janson, S. Bonner-Weir, R. Ritzel, R. A. Rizza, and P. C. Butler, " $\beta$-cell deficit and increased $\beta$-cell apoptosis in humans with type 2 diabetes," Diabetes, vol. 52, no. 1, pp. 102110, 2003.

[2] L. L. Baggio and D. J. Drucker, "Biology of incretins: GLP-1 and GIP," Gastroenterology, vol. 132, no. 6, pp. 2131-2157, 2007.

[3] J. Buteau, W. El-Assaad, C. J. Rhodes, L. Mosenberg, E. Joly, and M. Prentki, "Glucagon-like peptide-1 prevents beta cell glucolipotoxicity," Diabetologia, vol. 47, no. 5, pp. 806-815, 2004.

[4] L. Elghazi, N. Balcazar, and E. Bernal-Mizrachi, "Emerging role of protein kinase $\mathrm{B} /$ Akt signaling in pancreatic $\beta$-cell mass and function," International Journal of Biochemistry and Cell Biology, vol. 38, no. 2, pp. 157-163, 2006.

[5] S.-J. Kim, K. Winter, C. Nian, M. Tsuneoka, Y. Koda, and C. H. S. McIntosh, "Glucose-dependent insulinotropic polypeptide (GIP) stimulation of pancreatic $\beta$-cell survival is dependent upon phosphatidylinositol 3-kinase (PI3K)/protein kinase B (PKB) signaling, inactivation of the Forkhead transcription factor Foxol, and down-regulation of bax expression," Journal of Biological Chemistry, vol. 280, no. 23, pp. 22297-22307, 2005.

[6] B. D. Manning and L. C. Cantley, "AKT/PKB signaling: navigating downstream," Cell, vol. 129, no. 7, pp. 1261-1274, 2007.

[7] Q. Wang, L. Li, E. Xu, V. Wong, C. Rhodes, and P. L. Brubaker, "Glucagon-like peptide-1 regulates proliferation and apoptosis via activation of protein kinase B in pancreatic INS-1 beta cells," Diabetologia, vol. 47, no. 3, pp. 478-487, 2004.

[8] M. Ferdaoussi, S. Abdelli, J.-Y. Yang et al., "Exendin-4 protects $\beta$-cells from interleukin- $\beta$-induced apoptosis by interfering with the c-Jun $\mathrm{NH}_{2}$-terminal kinase pathway," Diabetes, vol. 57, no. 5, pp. 1205-1215, 2008.
[9] L. Li, W. El-Kholy, C. J. Rhodes, and P. L. Brubaker, "Glucagonlike peptide-1 protects beta cells from cytokine-induced apoptosis and necrosis: role of protein kinase B," Diabetologia, vol. 48, no. 7, pp. 1339-1349, 2005.

[10] B. Yusta, L. L. Baggio, J. L. Estall et al., "GLP-1 receptor activation improves $\beta$ cell function and survival following induction of endoplasmic reticulum stress," Cell Metabolism, vol. 4, no. 5, pp. 391-406, 2006.

[11] C. E. Wrede, L. M. Dickson, M. K. Lingohr, I. Briaud, and C. J. Rhodes, "Protein kinase B/Akt prevents fatty acid-induced apoptosis in pancreatic $\beta$-cells (INS-1)," The Journal of Biological Chemistry, vol. 277, no. 51, pp. 49676-49684, 2002.

[12] S. C. Martinez, K. Tanabe, C. Cras-Méneur, N. A. Abumrad, E. Bernal-Mizrachi, and M. A. Permutt, "Inhibition of Foxol protects pancreatic islet $\beta$-cells against fatty acid and endoplasmic reticulum stress-induced apoptosis," Diabetes, vol. 57, no. 4, pp. 846-859, 2008.

[13] J.-Y. Kim, D.-M. Lim, H.-S. Park et al., "Exendin-4 protects against sulfonylurea-induced $\beta$-cell apoptosis," Journal of Pharmacological Sciences, vol. 118, no. 1, pp. 65-74, 2012.

[14] L. Farilla, A. Bulotta, B. Hirshberg et al., "Glucagon-like peptide 1 inhibits cell apoptosis and improves glucose responsiveness of freshly isolated human islets," Endocrinology, vol. 144, no. 12, pp. 5149-5158, 2003.

[15] E. Favaro, R. Granata, I. Miceli et al., "The ghrelin gene products and exendin-4 promote survival of human pancreatic islet endothelial cells in hyperglycaemic conditions, through phosphoinositide 3-kinase/Akt, extracellular signal-related kinase (ERK)1/2 and cAMP/protein kinase A (PKA) signalling pathways," Diabetologia, vol. 55, no. 4, pp. 1058-1070, 2012.

[16] M. Cnop, "Fatty acids and glucolipotoxicity in the pathogenesis of type 2 diabetes," Biochemical Society Transactions, vol. 36, no. 3, pp. 348-352, 2008.

[17] V. Poitout and R. P. Robertson, "Glucolipotoxicity: fuel excess and $\beta$-cell dysfunction," Endocrine Reviews, vol. 29, no. 3, pp. 351-366, 2008.

[18] M. Prentki and C. J. Nolan, "Islet $\beta$ cell failure in type 2 diabetes," The Journal of Clinical Investigation, vol. 116, no. 7, pp. 1802-1812, 2006.

[19] M. L. Elks, "Chronic perifusion of rat islets with palmitate suppresses glucose- stimulated insulin release," Endocrinology, vol. 133, no. 1, pp. 208-214, 1993.

[20] C. L. Kelpe, P. C. Moore, S. D. Parazzoli, B. Wicksteed, C. J. Rhodes, and V. Poitout, "Palmitate inhibition of insulin gene expression is mediated at the transcriptional level via ceramide synthesis," The Journal of Biological Chemistry, vol. 278, no. 32, pp. 30015-30021, 2003.

[21] R. Lupi, F. Dotta, L. Marselli et al., "Prolonged exposure to free fatty acids has cytostatic and pro-apoptotic effects on human pancreatic islets: evidence that $\beta$-cell death is caspase mediated, partially dependent on ceramide pathway, and Bcl-2 regulated," Diabetes, vol. 51, no. 5, pp. 1437-1442, 2002.

[22] I. Maestre, J. Jordán, S. Calvo et al., "Mitochondrial dysfunction is involved in apoptosis induced by serum withdrawal and fatty acids in the $\beta$-cell line INS-1," Endocrinology, vol. 144, no. 1, pp. 335-345, 2003.

[23] J. D. McGarry, "What if Minkowski had been ageusic? An alternative angle on diabetes," Science, vol. 258, no. 5083, pp. 766-770, 1992.

[24] G. M. Reaven, C. Hollenbeck, C.-Y. Jeng, M. S. Wu, and Y.-D. I. Chen, "Measurement of plasma glucose, free fatty acid, lactate, 
and insulin for $24 \mathrm{~h}$ in patients with NIDDM,' Diabetes, vol. 37, no. 8, pp. 1020-1024, 1988.

[25] W. El-Assaad, J. Buteau, M.-L. Peyot et al., "Saturated fatty acids synergize with elevated glucose to cause pancreatic $\beta$-cell death," Endocrinology, vol. 144, no. 9, pp. 4154-4163, 2003.

[26] K. Maedler, J. Oberholzer, P. Bucher, G. A. Spinas, and M. Y. Donath, "Monounsaturated fatty acids prevent the deleterious effects of palmitate and high glucose on human pancreatic $\beta$ cell turnover and function," Diabetes, vol. 52, no. 3, pp. 726-733, 2003.

[27] C. J. Nolan, M. S. R. Madiraju, V. Delghingaro-Augusto, M.-L. Peyot, and M. Prentki, "Fatty acid signaling in the $\beta$-cell and insulin secretion," Diabetes, vol. 55, supplement 2, pp. S16-S23, 2006.

[28] S. M. Parker, P. C. Moore, L. M. Johnson, and V. Poitout, "Palmitate potentiation of glucose-induced insulin release: a study using 2-bromopalmitate," Metabolism: Clinical and Experimental, vol. 52, no. 10, pp. 1367-1371, 2003.

[29] D. J. Drucker and M. A. Nauck, "The incretin system: glucagonlike peptide-1 receptor agonists and dipeptidyl peptidase-4 inhibitors in type 2 diabetes," The Lancet, vol. 368, no. 9548, pp. 1696-1705, 2006.

[30] J. J. Holst and C. Ørskov, “The incretin approach for diabetes treatment: modulation of islet hormone release by GLP-1 agonism," Diabetes, vol. 53, no. 3, pp. S197-S204, 2004.

[31] Q. Wang and P. Brubaker, "Glucagon-like peptide-1 treatment delays the onset of diabetes in 8 week-old db/db mice," Diabetologia, vol. 45, no. 9, pp. 1263-1273, 2002.

[32] I. Briaud, M. K. Lingohr, L. M. Dickson, C. E. Wrede, and C. J. Rhodes, "Differential activation mechanisms of Erk-1/2 and p70S6K by glucose in pancreatic $\beta$-cells," Diabetes, vol. 52, no. 4, pp. 974-983, 2003.

[33] S. Costes, C. Broca, G. Bertrand et al., "ERK1/2 control phosphorylation and protein level of cAMP-responsive elementbinding protein: a key role in glucose-mediated pancreatic $\beta$ cell survival," Diabetes, vol. 55, no. 8, pp. 2220-2230, 2006.

[34] T. Mandrup-Poulsen, " $\beta$-cell apoptosis: stimuli and signaling," Diabetes, vol. 50, supplement 1, pp. S58-S63, 2001.

[35] K. Maedler, J. Størling, J. Sturis et al., "Glucose- and interleukin$1 \beta$-induced $\beta$-cell apoptosis requires $\mathrm{Ca}^{2+}$ influx and extracellular signal-regulated kinase (ERK) $1 / 2$ activation and is prevented by a sulfonylurea receptor 1 /inwardly rectifying $\mathrm{K}^{+}$channel 6.2 (SUR/Kir6.2) selective potassium channel opener in human islet," Diabetes, vol. 53, no. 7, pp. 1706-1713, 2004.

[36] C. J. Marshall, "Specificity of receptor tyrosine kinase signaling: transient versus sustained extracellular signal-regulated kinase activation," Cell, vol. 80, no. 2, pp. 179-185, 1995.

[37] E. N. Gurzov and D. L. Eizirik, "Bcl-2 proteins in diabetes: mitochondrial pathways of $\beta$-cell death and dysfunction," Trends in Cell Biology, vol. 21, no. 7, pp. 424-431, 2011.

[38] G. Szabadkai and M. R. Duchen, "Mitochondria mediated cell death in diabetes," Apoptosis, vol. 14, no. 12, pp. 1405-1423, 2009.

[39] S. Cagnol and J.-C. Chambard, "ERK and cell death: mechanisms of ERK-induced cell death-apoptosis, autophagy and senescence," FEBS Journal, vol. 277, no. 1, pp. 2-21, 2010.

[40] A. Bonni, A. Brunet, A. E. West, S. R. Datta, M. A. Takasu, and M. E. Greenberg, "Cell survival promoted by the Ras-MAPK signaling pathway by transcription-dependent and -independent mechanisms," Science, vol. 286, no. 5443, pp. 1358-1362, 1999.
[41] M.-J. Boucher, J. Morisset, P. H. Vachon, J. C. Reed, J. Lainé, and N. Rivard, "MEK/ERK signaling pathway regulates the expression of Bcl-2, Bcl- $\mathrm{X}_{\mathrm{L}}$, and $\mathrm{Mcl}-1$ and promotes survival of human pancreatic cancer cells," Journal of Cellular Biochemistry, vol. 79, no. 3, pp. 355-369, 2000.

[42] H. Ishihara, T. Asano, K. Tsukuda et al., "Pancreatic $\beta$ cell line MIN6 exhibits characteristics of glucose metabolism and glucose-stimulated insulin secretion similar to those of normal islets," Diabetologia, vol. 36, no. 11, pp. 1139-1145, 1993.

[43] M. Skelin, M. Rupnik, and A. Cencic, "Pancreatic beta cell lines and their applications in diabetes mellitus research," ALTEX, vol. 27, no. 2, pp. 105-113, 2010. 


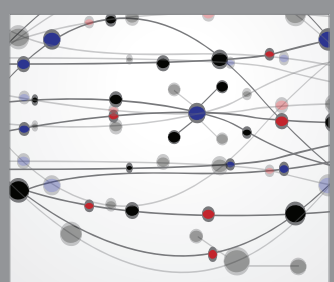

The Scientific World Journal
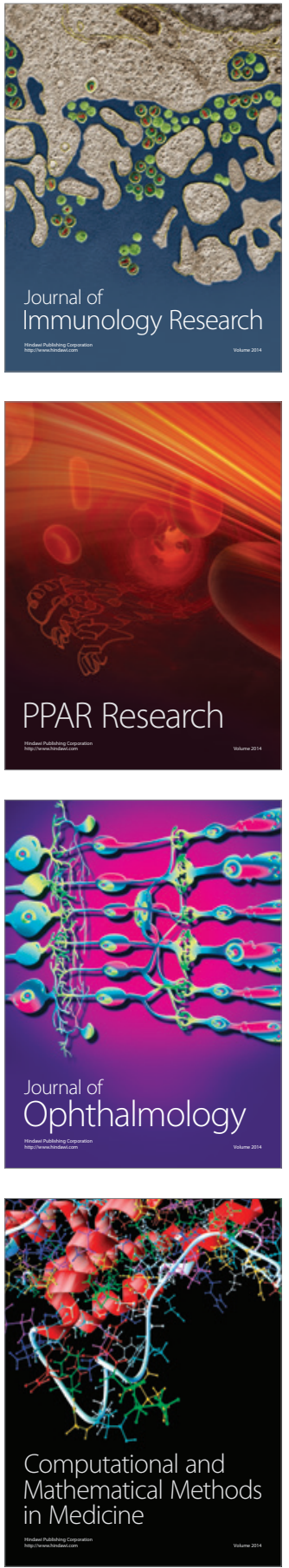

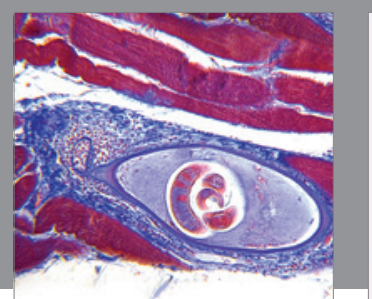

Gastroenterology Research and Practice

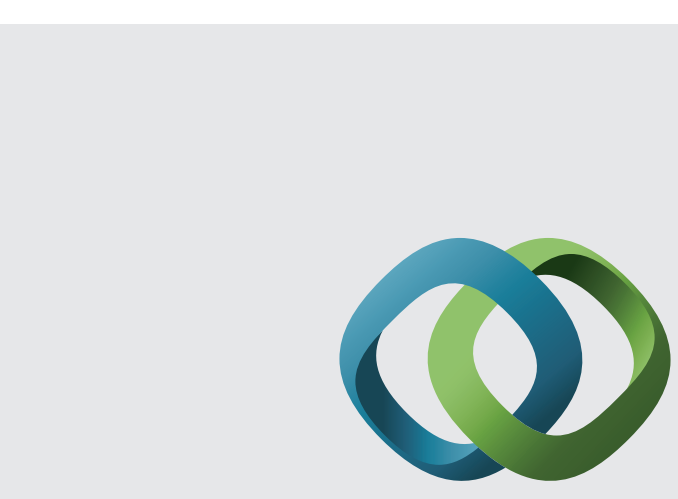

\section{Hindawi}

Submit your manuscripts at

http://www.hindawi.com
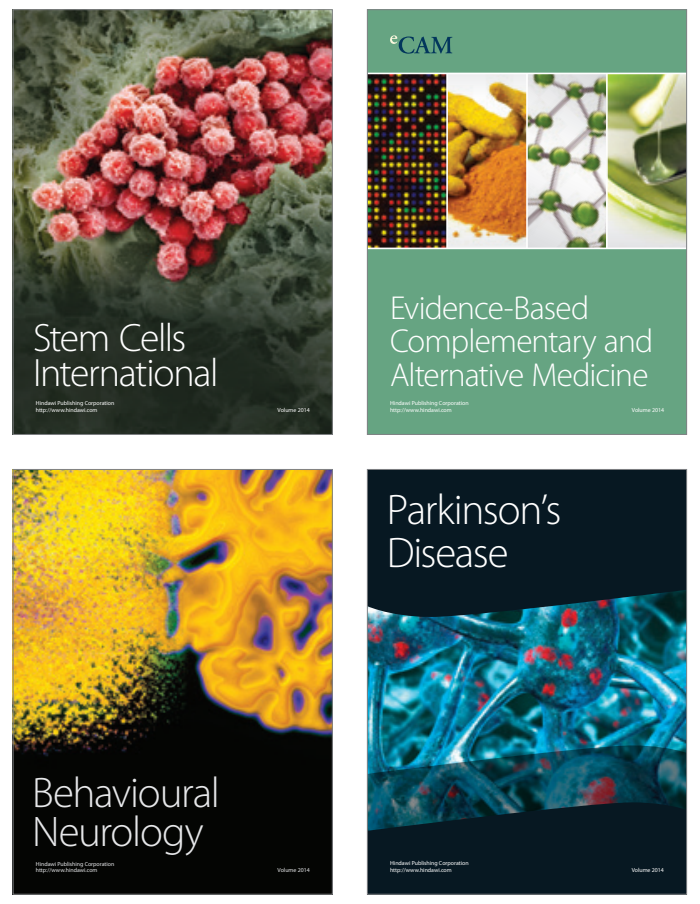
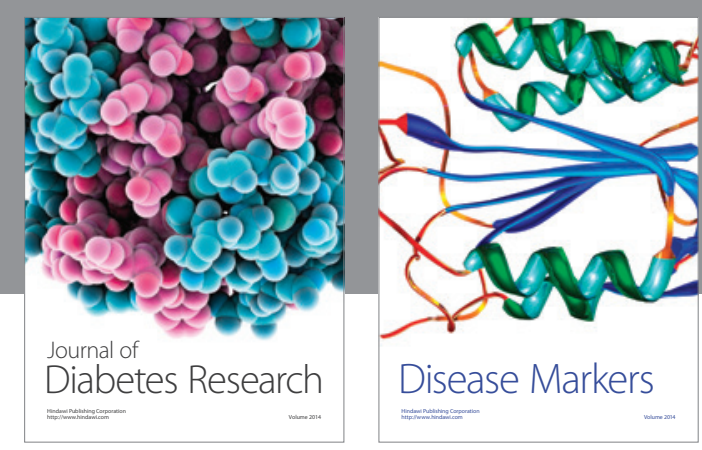

Disease Markers
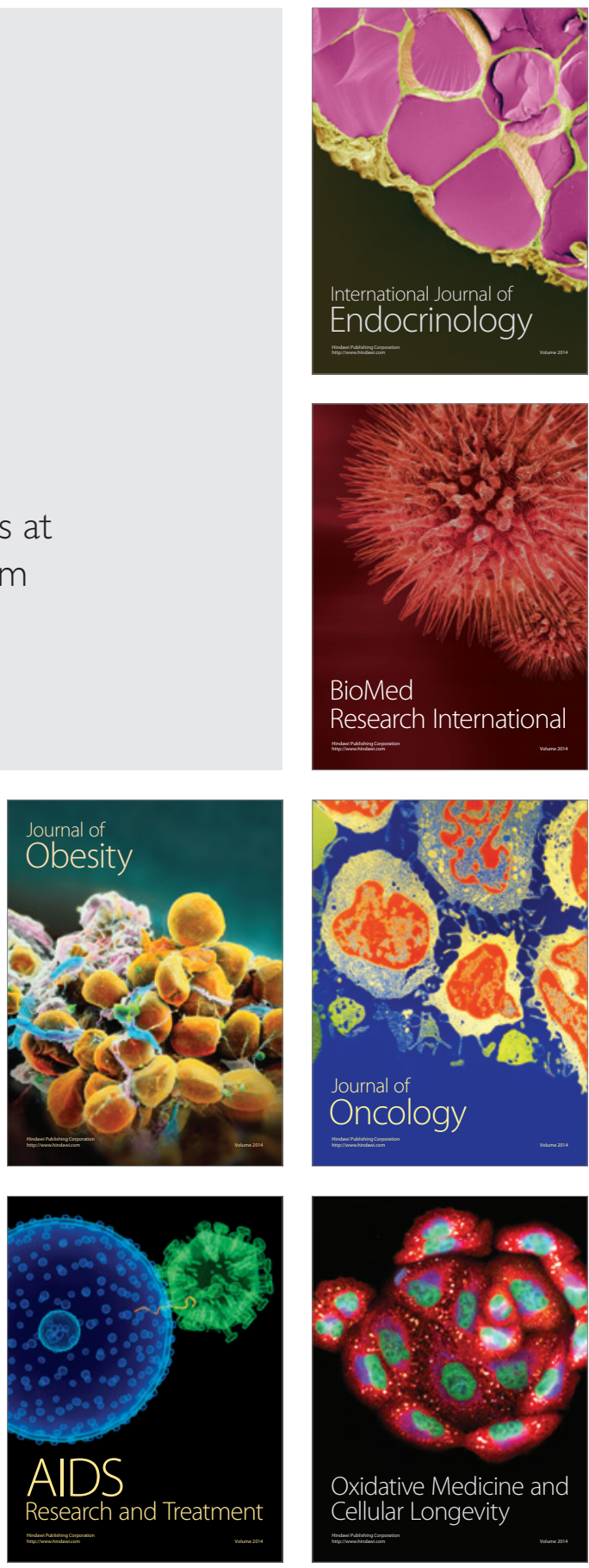